\title{
G) Histicátórica
}

\section{Experiências de luta, sobrevivência e resistência de mulheres negras}

\author{
MARQUES, Danilo Luiz. Os caminhos para a Liberdade de Escravizadas e Africanas livres em \\ Maceió (I849-I888). Blumenau: Nova Letra, 2016. I86p.
}

Marcos Antonio Batista da Silva"

Danilo Luiz Marques é graduado em História pela Universidade Federal de Alagoas (UFAL), mestre em História Social pela Pontifícia Universidade Católica de São Paulo (PUC/SP), e doutor em História Social (PUC/SP),com período sanduíche na Michigan State University, nos Estados Unidos. Professor da rede pública estadual de São Paulo, com experiência na área de Arquivologia e História, e tem se dedicado a pesquisas, a saber : História do Brasil no século XIX, Resistência Escrava, Gênero e Escravidão, História e Historiografia Alagoana.

O livro do autor é produzido originalmente como dissertação de mestrado em História Social, pela PUC/SP, com o título de "Sobreviver e Resistir: os caminhos para liberdade de africanas livres e escravas em Maceió (I849-I888)", defendida no ano de 20I3. A obra do jovem historiador apresenta um caprichado mergulho na realidade das experiências de vida de mulheres africanas livres e escravizadas na cidade de Maceió, Alagoas, Brasil, na metade do século XIX, bem como descreve acertadamente a luta destas mulheres por sobrevivência e resistência no período de escravidão no país. O resultado é uma leitura aprazível e um texto que contribui para o debate sobre gênero e escravidão no Brasil do século XIX.

A temporalidade do trabalho durante o período investigado (I849 a I888) cobre fatos históricos importantes da época: I849, ano em que ocorreram vários desembarques ilegais de navios negreiros na costa alagoana, ocasionando a chegada de muitas mulheres africana livres; a Lei Eusébio Queiróz que foi sancionada em I850 e proibia o tráfico de escravizados para o Brasil; a Lei do ventre livre (I87I); a Lei dos Sexagenários (I885), bem como o ano de

\footnotetext{
"Doutor em Psicologia Social pela Pontifícia Universidade Católica de São Paulo (PUC-SP). Investigador em pós-doutoramento no Centro de Estudos Sociais da Universidade de Coimbra.
} 
I888, quando da abolição da escravidão no Brasil, além do período em que Maceió foi recém tornada capital da Província de Alagoas. Neste contexto, Danilo Marques apresenta como se configurava a cidade de Maceió na época em que se consolidava como novo núcleo demográfico-econômico da região alagoana.

Ao retratar o cotidiano de mulheres africanas livres e escravizadas na cidade de Maceió, o autor assinala que estas desempenharam trabalhos como os de lavadeiras, quituteiras, doceiras, amas de leite, mucamas, bem como frisa, que estas lutavam diariamente contra a hegemonia escravista. A mão-de-obra feminina era muito presente em Maceió para os serviços domésticos, em residência de senhores de engenho, políticos, comerciantes e autoridades.

No capítulo i da obra é abordado como a cidade de Maceió se consolidou como o principal polo urbano da Província de Alagoas, o processo de socialização, isto é, as sociabilidades negras, bem como a presença das mulheres africanas escravizadas e livres no espaço urbano. Em síntese, o autor através de uma revisão de documentação histórica, dá ênfase à cidade de Maceió; ao cotidiano e resistência da população negra em Maceió do século XIX, retratando as atividades das mulheres africanas livres e escravizadas.

Ao analisar o Relatório Provincial de Alagoas do ano de I869, localizamos em anexo os Apontamentos sobre diversos assumptos geográficosadministrativos da Província de Alagoas, escrito por José Alexandrino Dias de Moura. Este documento - que descreve Maceió ...expõe o desenvolvimento urbano da cidade entre as décadas de I840 e i860: "Maceió tem augmentado e progredido consideravelmente nestes últimos 20 annos e é hoje uma linda cidade ornada de bons prédios particulares e elegantes edifícios públicos" (sic.) 5, como a Casa de Detenção, o Hospital da Caridade, o Palácio do Presidente da Província, a Assembleia Legislativa Provincial, a Câmara Municipal e o Mercado Público (MARQUES,2013,p.73).

Além de construções de várias igrejas (I840-1850), a saber: Nossa Senhora do Rosário, Nossa Senhora do Livramento, Nosso Senhor Bom Jesus dos Martírios e a Matriz de Nossa Senhora dos Prazeres. Vale ressaltar que o desenvolvimento urbano que perpassou a cidade de Maceió ao longo do século XIX, especialmente após o ano de I839, quando foi alçada a capital da Província, foi acompanhado também de um crescimento 
demográfico. Em I847 a população de Maceió contava com I6.064 pessoas, (II. 902 livres e 4.I62 escravizados). Em I855, dos 25.I35 habitantes, 6.230 eram escravizados. No ano de I870 computava uma população de 28.630 pessoas, desta, 4.822 continuavam escravizados. $\mathrm{Ou}$ seja, a população escravizada era em média $25 \%$ entre as décadas de I840 e I850, porém no anoi 870 caiu para $16 \%$.

O contexto sócio-histórico da obra mostra que a historiografia brasileira tem se dedicado com ênfase ao estudo da escravidão e da presença africana nas cidades durante o século XIX, desse modo, contribuindo para o preenchimento de lacunas na história da escravidão, e retratando particularidades das vivências urbanas. As cidades eram um centro para onde confluíam homens livres, escravizados e libertos em busca de serviços de ganho no comércio, ou fugidos das fazendas em busca de esconderijos.

Danilo Marques entende que a proximidade entre a zona rural e urbana é fator importante para a compreensão das cidades brasileiras no século XIX, inclusive a de Maceió, com sua urbanização a partir de I839. Mas não podemos esquecer-nos da dura luta em busca de liberdade que os escravizados travavam diariamente contra a hegemonia senhorial.

Ao retratar o cotidiano da Maceió do século XIX, no que tange as tensões sociais inerentes ao período após a promulgação da lei Eusébio de Queiroz, o autor da ênfase aos quilombos que existiam nos arredores da cidade, reduto de escravizados fugidos. A população escravizada desenvolvia estratégias e necessitava de espaços (esconderijos e quilombos) para se camuflar, ou seja, uma forma encontrada para resistir ao controle dos senhores.

Segundo a literatura, a região de Alagoas foi marcada por constantes movimentações de navios negreiros vindos do continente africano e/ou de outras Províncias, por exemplo, Bahia e Pernambuco. O autor destaca ainda, o fato que "na cidade de Maceió, ao longo do século XIX, existia a presença das chamadas figuras intermediárias da escravidão, como os africanos livres"(MARQUES, 20I3,p.48). Desse modo, o autor volta seu olhar sobre eles, tirando-os do silêncio, evidenciando as desconhecidas experiências de vida dessa população que não era considerada escravizada, mas que viveu em estreita relação com a escravidão.

Maceió foi marcada pela intensa movimentação da população negra na cidade com presença dos escravizados e dos africanos livres que ocuparam as ruas, praças, becos e locais desertos dos arredores da capital alagoana para resistir à escravidão, mas também para buscar seus meios para garantir sobrevivência. Em Maceió os escravizados estavam inseridos em trabalhos domésticos, e outras funções, a saber: pedreiro, ferreiro, canoeiro, 
vendedores de frutas, aves, peixes,jornaleiros, etc. Mas antes disto, no cotidiano os negros escravizados e libertos tiveram que se defrontar com os encargos de sobreviver, com as exigências impostas e criar estratégias à resistência contra a escravidão.

Entende-se que na socieade brasileira, as desigualdades sociais vêm de longa data, e são atribuídas à herança do passado escravista, à política de branqueamento da passagem do século XIX para o XX, à histórica condescendência das elites brasileiras com desigualdades sociais e ao racismo estrutural e simbólico contemporâneo. $\mathrm{Na}$ conemporaneidade, estudos quantitativos e qualitativos sobre a desigualdade racial no Brasil continuam sendo produzidos, e são um constante lembrete das injustiças raciais do Brasil. Um exemplo é o "Relatório Anual de Desigualdades Raciais no Brasil 2009-20Io", organizado por Paixão (20I0). Tais estudos reforçam a necessidade de políticas de ação afirmativa para a população negra ,em epecial, educação e mercado de trabalho. Políticas essas que, em médio prazo, possam garantir uma maior equidade de oportunidades e de padrão de vida, alterando a situação de desigualdade, e possibilitando a inclusão da população negra nos segmentos mais dinâmicos do sistema educacional e de maior renda no mercado de trabalho (SILVA,20I6).

O Capítulo 2 discute as categorias dos africanos "livres" no Brasil e seu papel na manutenção da escravidão. Assim, Danilo Marques assinala que na cidade de Maceió, ao longo do século XIX, existia a presença dos africanos livres. Para o autor, na contemporaneidade, "a historiografia da escravidão no Brasil tem voltado seus olhares sobre eles, tirando do silêncio as desconhecidas experiências de vida desta população que não era considerada escrava, entretanto, viveu em estreita relação com a escravidão"(MARQUES,2013,p.85).Danilo Marques, ao efetuar análise sobre a documentação da Curadoria dos Africanos Livres de Alagoas, localizada no Arquivo Público do Estado de Alagoas, percebeu uma forte presença desta categoria no quotidiano da Maceió do século XIX, isto é, o autor frisa que foi de grande valia, compreender a sociabilidade negra na cidade. “... a curadoria expediu e recebeu ofícios e demais papéis sobre esta população durante trinta anos, de I836 a I866. Esta documentação nos permite detectar aspectos da vida cotidiana desta população como a formação de famílias, trabalho, resistência e transgressões(MARQUES,20I3,p. 85).

Danilo Marques perpassa a luta diária da busca de emancipação das africanas, a saber: Benedita, Roza, Henriqueta, Margarida, Luisa, Luiza. Mulheres que habitaram a cidade de Maceió após serem apreendidas como contrabando no litoral norte de Alagoas. Vale dizer que: 
O quotidiano das escravas e africanas livres na Maceió do século XIX foi marcado pelo trabalho doméstico e pelos serviços de ganho realizados nas ruas da cidade, principalmente o comércio ambulante. Com isto, elas desenvolviam seus arranjos de sobrevivência e buscavam os caminhos para a liberdade, estes serviços poderiam estar ligados à questão da subsistência, mas também era uma forma de constituir pecúlio para quem sonhava em conquistar a emancipação(...).Foram ansiosas e desinquietas pela postergação da solução emancipacionista e manifestaram seus descontentamentos, sejam com movimentos de rebeldia ou buscando os meios legais possíveis entre as brechas da legislação da época. (MARQUES,2013,p.93-94).

Isto é, estas mulheres ainda enfrentavam um típico problema do estado imperial ou dos latifundiário, patrões e empresários da época.

O capitulo 3 apresenta particularidades das vidas das escravizadas Feliciana, Cristina, Ana, Joana, Fé e Alma. Estas mulheres recorreram às táticas de resistência e sobrevivência para serem alforriadas, afirmando-se como protagonistas de suas histórias. De um lado, a conjuntura do Brasil do século XIX apresentava vários debates acerca da escravidão, de outro, mostrava que foram criados mecanismos para sua manutenção, discutia-se também as condições em que a população cativa poderia, de forma "legítima", mudar seu status jurídico e conquistar a liberdade.

Por fim, o autor mostra que seria ingenuidade por parte dos historiadores acreditarem que os cativos não tinham conhecimentos dos conflitos políticos que marcaram a conjuntura do século XIX, além de frisar que é de vital importância para se compreender a abolição da escravidão no Brasil, sob a ótica da participação dos escravizados, forros e homens livres pobres, e não apenas como um evento produzido pelas elites e para as elites no Brasil. Danilo Marques assinala ainda, que as mulheres africanas livres e escravizadas, apesar de toda uma situação adversa, eram sabedoras das possibilidades que existiam na conjuntura histórica que viveram, desse modo experimentaram projetos de liberdade desenvolvendo estratégias de sobrevivência e buscando os caminhos para a liberdade.

Diante destas e de outras questões apresentadas no livro "Os caminhos para a Liberdade de Escravizadas e Africanas livres em Maceió (I849-I888)”, Danilo Luiz Marques, ao reconhecer a importância e a contribuição da população negra no processo de formação da sociedade brasileira,contribui para o debate sobre esta população, e se associa ao coro que questiona as desigualdades sociais e colabora com essa luta. 


\section{Referências}

MARQUES, Danilo Luiz. Escravidão, Quotidiano e Gênero na Emergente Capital Alagoana (I849-I888). Sankofa (São Paulo), São Paulo, v. 6, n. II, p. 7I-95, ago. 2013. Disponível em: <https:/www.revistas.usp.br/sankofa/article/view/88912>. Acesso em: 26 abr. 20I8. doi:http://dx.doi.org/IO.II606/issn.I983-6023.sank.20I3.889I2.

MARQUES, Danilo Luiz. Sobreviver e resistir: os caminhos para liberdade de africanas livres e escravas em Maceió (I849-I888). 2013. I45 f. Dissertação (Mestrado em História Social) - Programa de Pós-graduados em Históira Social, Pontifícia Universidade Católica de São Paulo, São Paulo ,2013. Disponível em: < https://tede2.pucsp.br/bitstream/handle/12792/I/Danilo\%2oLuiz\%2oMarques.pdf https://repositorio. unesp.br/handle/II449/86647>. Acesso em: 26 mai. 2018.

SILVA,M.A.B. Discursos étnico-raciais de pesquisdores (as) negros(as) na pós-graduação: acesso, permanência, apoios e barreiras.Psicologia em Revista, Belo Horizonte, v. 22, n. 2, p. 537-540, ago. 2016.

PAIXÃO, Marcelo. (Org.). Relatório anual das desigualdades raciais no Brasil: 2009-20Io. Rio de Janeiro, Universidade Estadual do Rio de Janeiro, Rio de Janeiro, 20Io.Disponível em:< $\quad$ https://www.geledes.org.br/wp-content/uploads/20I4/05/Relat\%C3\%B3rio_200920IO.pdf>.Acesso em : Io abr.20I8.

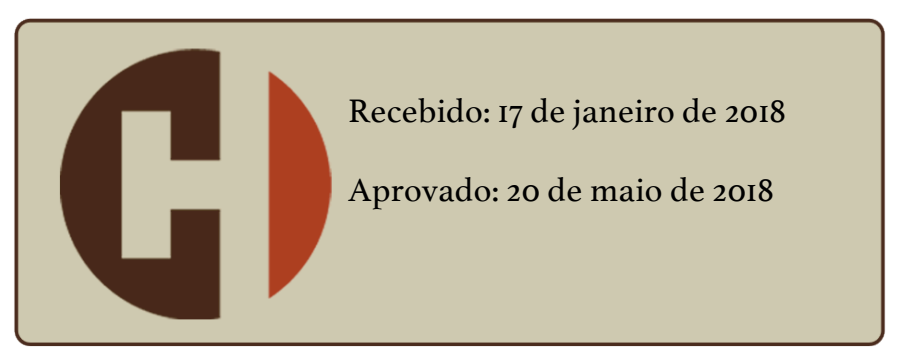

